\title{
Binding Sites of Attachment-Inhibiting Monoclonal Antibodies and Antibodies from Patients on Peptide Fragments of the Mycoplasma pneumoniae Adhesin
}

\author{
ENNO JACOBS, ${ }^{1 *}$ BERNHARD GERSTENECKER, ${ }^{1}$ BEATRIX MADER, ${ }^{1}$ CHIEN-HUI HUANG ${ }^{2}$ \\ PING-CHUAN HU ${ }^{2}$ ROMAN HALTER ${ }^{3}$ AND WOLFGANG BREDT ${ }^{1}$ \\ Institute for Medical Microbiology and Hygiene, University of Freiburg, D-7800 Freiburg, Federal Republic of Germany ${ }^{\text {; }}$ \\ Department of Pediatric Infectious Diseases, University of North Carolina, Chapel Hill, North Carolina $27514^{2}$; and \\ Max-Planck Institute for Biology and Infection Genetics, D-7800 Tübingen, Federal Republic of Germany ${ }^{3}$
}

Received 27 July 1988/Accepted 15 November 1988

\begin{abstract}
The adherence protein (P1 protein) of Mycoplasma pneumoniae was purified by electroelution and cleaved with cyanogen bromide. The resulting peptides were separated by two-dimensional electrophoresis. Spots reacting in Western immunoblots with two attachment-inhibiting monoclonal antibodies were isolated, and the amino-terminal ends of these peptides were microsequenced. The two monoclonal antibodies had different binding sites. One was associated with the amino-terminal region of the whole P1 protein beginning at amino acid position 237, and the other was associated with amino acid position 702, which was localized approximately in the middle of the P1 amino acid sequence. Serum samples from three $M$. pneumoniae-infected patients were tested by Western blotting against the cyanogen bromide peptide pattern. All three serum samples reacted with peptide fragments beginning at amino acid position 702 , but the serum of only one patient also had antibodies against the oligopeptides beginning at amino acid position 237 . These results indicate that the corresponding epitopes of the P1 protein are also immunogenic if they are presented at the surface of the infecting organism.
\end{abstract}

The human pathogen Mycoplasma pneumoniae is able to bind to surfaces of respiratory cells or erythrocytes. The binding site of $M$. pneumoniae has been shown by electron microscopy to be a surface protein (P1 protein) which is localized mainly in the tip structure membrane of $M$. pneumoniae cells $(1,4,6)$. Monoclonal antibodies (MAbs) reacting with this adhesin inhibit the attachment of sheep erythrocytes to $M$. pneumoniae cell layers grown on plastic surfaces (12). These surface-exposed epitopes of $M$. pneumoniae membranes are also of special interest for $M$. pneumoniae serology $(7,9,14)$, because the sera of most patients suffering from $M$. pneumoniae infections contain adherenceinhibiting antibodies (12). Dallo et al. (2) have identified an adherence-mediating sequence by screening cloned P1 fragments with an adherence-inhibiting MAb. In this study we identified two other epitopes on the primary sequence of this molecule by another approach. The P1 protein was purified out of $M$. pneumoniae cells and cleaved with cyanogen bromide. The oligopeptides were separated two-dimensionally and were probed with adherence-inhibiting MAbs. Peptide spots reacting with the antibodies were microsequenced, and the resulting amino acid sequences of the amino termini of these peptides were localized on the P1 molecule, which was recently cloned and sequenced independently by Su et al. (19) and Inamine et al. (8). To obtain information about the immunogenicity of these epitopes during $M$. pneumoniae infections, the antibody activities of patient serum with these peptides were studied.

\section{MATERIALS AND METHODS}

Chemical cleavage of the P1 protein. The P1 protein was isolated out of $M$. pneumoniae $\mathrm{FH}$ as described previously (10). $\mathrm{P} 1$ protein $(1 \mathrm{mg})$ was cleaved for $18 \mathrm{~h}$ with cyanogen

\footnotetext{
* Corresponding author.
}

bromide as described by Kamp (13). Cyanogen bromide was extracted by gel filtration with prepacked PC-10 columns (Pharmacia, Freiburg, Federal Republic of Germany). The peptide solution was concentrated by ultrafiltration (centricon 10 cells; Amicon Corp., Lexington, Mass.) to a 50- $\mu$ l volume.

Peptide separation. Peptide $(150 \mu \mathrm{g})$ was separated by two-dimensional polyacrylamide gel electrophoresis according to the isoelectric point by isoelectric focusing in the first dimension ( $\mathrm{pH} 3$ to 10) and according to the molecular weight by sodium dodecyl sulfate-polyacrylamide gel electrophoresis in the second dimension ( $12 \%$ separating gel), as described by O'Farrell (17).

Epitope mapping. Isolated peptides were blotted to transfer membranes (Immobilon; Millipore Corp., Bedford, Mass.). The sera of patients suffering from $M$. pneumoniae disease or MAbs (62F2 and M-328) with attachment-inhibiting activity (12) were tested for antibody reactions with the peptide fragments by the Western immunoblot method (20).

Gas-phase sequencing of immobilized peptides. Gas-phase sequencing was performed on peptide spots which were cut out of transfer membranes and stained with Coomassie blue (16). The amino-terminal ends of the oligopeptides were sequenced by Edman degradation in a gas-phase protein sequencer (477A; Applied Biosystems). Phenylthiohydantoin derivates of amino acids were identified by reversephase chromatography as described by Lottspeich (15). The resulting sequence was localized on the known amino acid sequence of the $P 1$ protein $(8,19)$.

MAbs and patient sera. MAbs 62F2 and M-328 (8) (both immunoglobulin $\mathrm{G}$ [IgG]) were selected for activity against the $\mathrm{P} 1$ protein by using an enzyme-linked immunosorbent assay (ELISA) with purified P1 protein as the antigen and for adherence-inhibiting activity of sheep erythrocytes to adherent $M$. pneumoniae cells in microtiter plates as described 


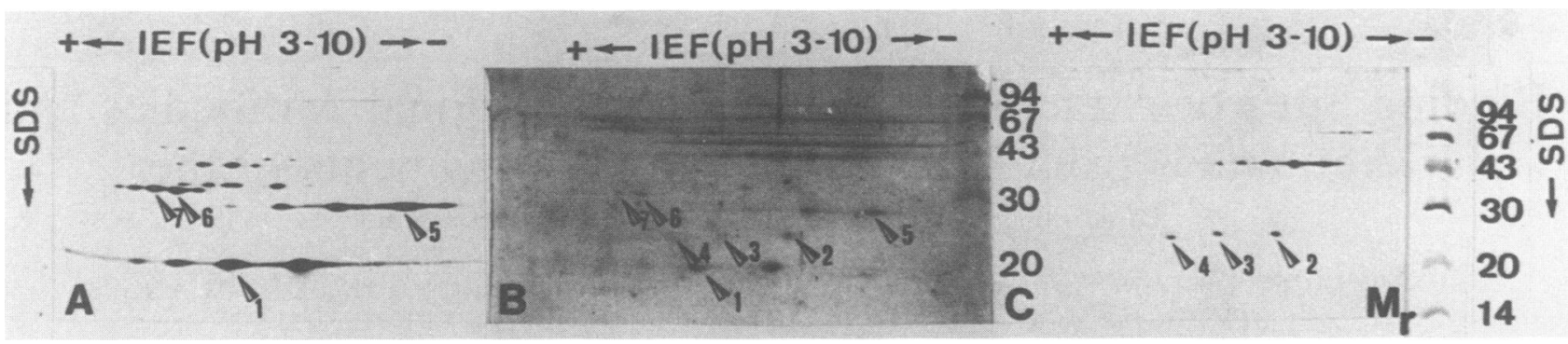

FIG. 1. MAb M-328 (A) and MAb 62F2 (C) show binding with microsequenced peptide fragments (1 to 7) of the cyanogen bromide-cleaved P1 protein by the Western immunoblot technique after separation of peptide fragments in a two-dimensional electrophoresis, Coomassie blue-stained peptide pattern (B). Molecular weight markers are indicated to the right of panels B and C (in thousands). Abbreviations: SDS, Sodium dodecyl sulfate; IEF, immunoelectrofocusing.

previously $(11,12)$. Paired sera of patients with clinical symptoms of respiratory diseases and pneumonia were tested for antibodies to $M$. pneumoniae by the complement fixation test, the P1 ELISA, and the adherence-inhibiting assay (12).

\section{RESULTS}

The P1 protein fragments obtained by cyanogen bromide cleavage were separated by two-dimensional electrophoresis. The fingerprints of Coomassie blue-stained peptides immobilized on transfer membranes are shown in Fig. 1B. To localize the MAb-binding sites on the $\mathrm{P} 1$ protein amino acid sequence, the $\mathrm{N}$ termini of peptide fragments with the lowest molecular weights were selected for microsequencing. Of these peptide spots, the N-terminal ends of peptide fragments 1 to 7 could be sequenced. MAb M-328 bound to peptide fragment 1 (Fig. 1A), which had an approximate

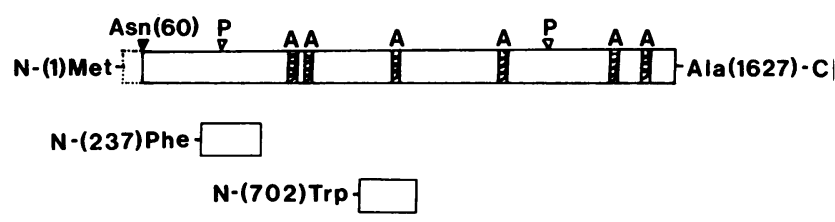

FIG. 2. Location of MAb-binding regions on the primary amino acid sequence of the $\mathrm{P} 1$ protein (MAb 62F2: $\mathrm{N}$-[237 amino acids]Phe; MAb M-328: N-[702 amino acids]-Trp). The whole P1 protein amino acid sequence with the precursor region of 59 amino acids beginning with $\mathrm{N}-(1$ amino acid)-Met and the mature $\mathrm{P} 1$ protein beginning with $\mathrm{N}-(60$ amino acids)-Asn are as described previously $(8,19)$. Predicted hydrophilic (P) and hydrophobic (A) surface protein sequences according to hydrophilic and hydrophobic plots are as described by Hopp and Woods (5) and Eisenberg et al. (3). molecular weight of 20,000 (about 160 amino acids), and peptide fragments 5,6 , and 7 , which each had a molecular weight of approximately 30,000 (about 250 amino acids). Microsequencing analysis of these four different peptides showed a common amino terminus of (N)WAWQVYN WSN. This sequence was localized in the middle of the P1 protein beginning at amino acid position 702 (Fig. 2). The second MAb, 62F2, bound to peptide fragments 2, 3, and 4 (Fig. 1C), which each had a molecular weight of approximately 25,000 (about 210 amino acids). Likewise, these peptides, possessed a common amino terminus beginning with (N)FGLKVKNAEA. This sequence was identical to a sequence near the amino terminus of the mature $\mathrm{P} 1$ protein starting at amino acid position 237 (Fig. 2).

To find out whether these attachment sites containing peptide fragments were immunogenic during $M$. pneumoniae diseases, serum samples from three patients suffering from $M$. pneumoniae infection with significant antibody rises in the complement fixation test and in the P1 protein ELISA and with increasing adherence-inhibiting antibodies were tested for IgG activity (Table 1). The second serum samples (reconvalescent phase) from all three patients reacted with peptide fragments $1,5,6$, and 7 (Fig. 3B, C, and D) and were identical to the binding site of MAb M-328. One serum sample also recognized peptide fragments 2,3 , and 4 , which were the binding sites of MAb 62F2 (Fig. 3D).

\section{DISCUSSION}

Studies about the relation between the structure and function of the P1 membrane protein are now possible because (i) the amino acid sequence is known $(8,19)$, (ii) the protein has been isolated (10), and (iii) MAbs especially directed to the attachment epitopes have been established in several laboratories $(1,4,6)$.

TABLE 1. Paired sera of three patients suffering from $M$. pneumoniae disease tested for antibody activity in the complement fixation test; in the P1 protein ELISA for IgG, IgM, and IgA; and for adherence-inhibiting antibodies

\begin{tabular}{|c|c|c|c|c|c|c|c|}
\hline \multirow{2}{*}{$\begin{array}{l}\text { Patient age } \\
\quad(y r)\end{array}$} & \multirow{2}{*}{ Clinical diagnosis } & \multirow{2}{*}{$\begin{array}{l}\text { Time (days) after } \\
\text { onset of symptoms }\end{array}$} & \multirow{2}{*}{$\begin{array}{c}\text { Complement fixation } \\
\text { titer }^{-1} \text { test }\end{array}$} & \multicolumn{3}{|c|}{ P1 ELISA titer $^{-1}$} & \multirow{2}{*}{$\begin{array}{l}\text { Adherence-inhibiting } \\
\text { antibody titer }\end{array}$} \\
\hline & & & & IgG & IgM & $\operatorname{Ig} \mathbf{A}$ & \\
\hline 47 & Atypical pneumonia & $\begin{array}{r}7 \\
16\end{array}$ & $\begin{array}{r}10 \\
240\end{array}$ & $\begin{array}{r}50 \\
6,400\end{array}$ & $\begin{array}{r}<50 \\
3,200\end{array}$ & $\begin{array}{r}<50 \\
3,200\end{array}$ & $\begin{array}{l}<2 \\
32\end{array}$ \\
\hline 14 & Pneumonia & $\begin{array}{r}7 \\
17\end{array}$ & $\begin{array}{r}10 \\
120\end{array}$ & $\begin{array}{l}<50 \\
800\end{array}$ & $\begin{array}{l}<50 \\
800\end{array}$ & $\begin{array}{r}<50 \\
400\end{array}$ & $\begin{array}{r}<2 \\
8\end{array}$ \\
\hline 28 & Pneumonia & $\begin{array}{r}8 \\
19\end{array}$ & $\begin{array}{r}30 \\
240\end{array}$ & $\begin{array}{r}50 \\
3,200\end{array}$ & $\begin{array}{r}50 \\
400\end{array}$ & $\begin{array}{r}<50 \\
800\end{array}$ & $\begin{array}{l}<2 \\
16\end{array}$ \\
\hline
\end{tabular}




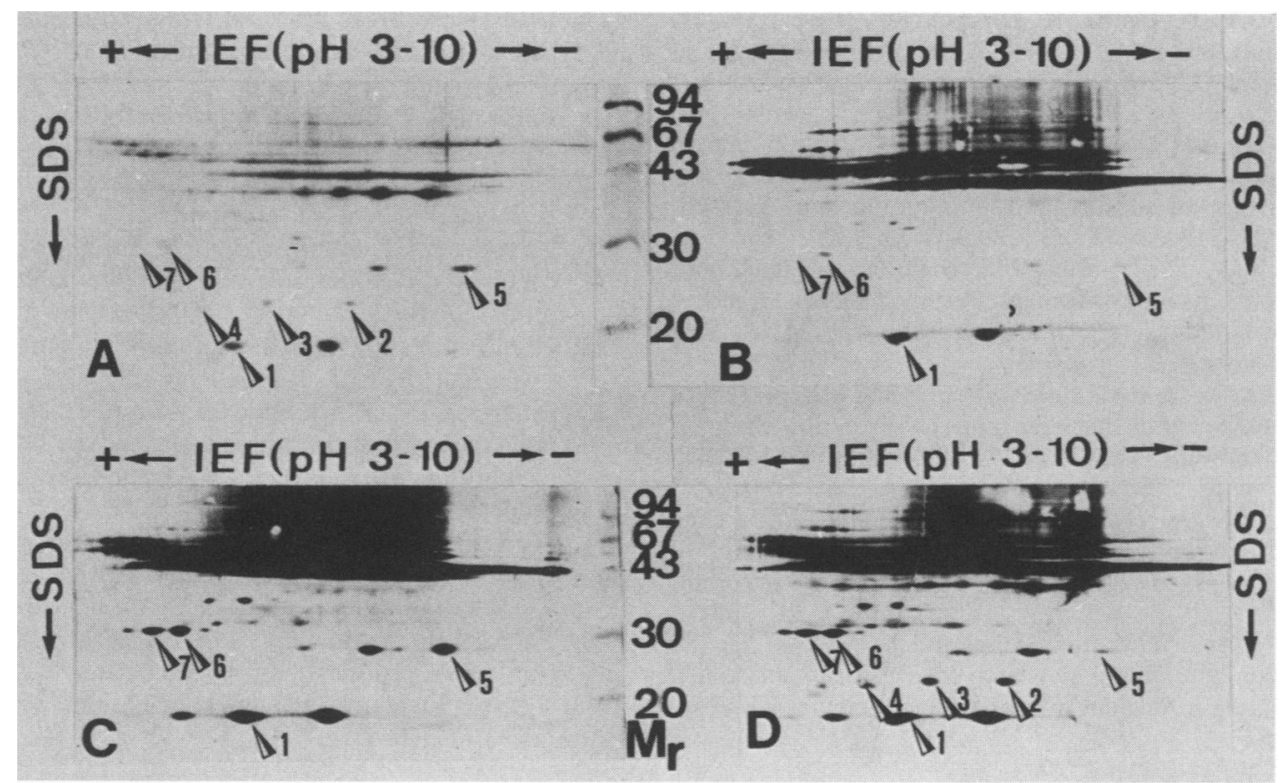

FIG. 3. Binding of IgG in the serum of patients suffering from $M$. pneumoniae diseases to peptide fragments of the chemically cleaved P1 protein. (A) Coomassie blue-stained peptide fragments after separation by two-dimensional electrophoresis. Different patient serum samples are given in panels B to D (B, 47-year-old patient; C, 28-year-old patient, D, 14-year-old patient; see Table 1). Molecular weights are given in thousands. Abbreviations: SDS, Sodium dodecyl sulfate; IEF, immunoelectrofocusing.

Studies on the P1 protein obtained by cloning and expression in Escherichia coli have been limited until now by the premature termination of $M$. pneumoniae proteins in $E$. coli because of the presence of UGA codons, which are read as tryptophan in $M$. pneumoniae instead of as a termination codon $(2,18)$. In our study the whole $P 1$ protein was therefore isolated out of $M$. pneumoniae cells and chemically fragmented to oligopeptides.

The two MAbs with attachment-inhibiting activities shared binding to different peptide fragments of the cyanogen bromide-cleaved P1 protein. Peptide fragments 1 to 7 could be analyzed by the microsequence method that was used, but the other peptide spots contained too little protein or the $\mathbf{N}$ terminus was blocked. Interestingly, peptide fragments $1,5,6$, and 7 and peptide fragments 2,3 , and 4 contained two different attachment sites which were localized at quite different positions in the primary sequence of the P1 protein. According to the analysis of Eisenberg et al. (3), these two regions are separated by two hydrophobic sequences with $\alpha$-helices long enough to theoretically cross biomembranes. Recently, Dallo et al. (2) showed another attachment epitope near the $\mathrm{C}$ terminus. From these results one might speculate that the native attachment epitope on the tertiary structure consists of several surface-exposed loops.

IgG in the second serum samples (reconvalescent phase) from all three patients reacted especially with the peptide fragments recognized by MAb M-328. The serum of only one patient also developed IgG activity to MAb 62F2 binding sites. The first serum samples from the same patients showed only a very faint fingerprint, especially to peptide fragment 1 (data not shown).

Apparently, during $M$. pneumoniae diseases the immune system of infected patients recognizes parts of the $\mathrm{P} 1$ protein which are involved in attachment. However, the peptide fragments of about 20,25 , and 30 kilodaltons were still too large to determine whether the attachment epitopes of the two MAbs and the binding sites of antibodies from patient sera were identical or whether other regions close to these attachment epitopes were involved in the antibody responses of the infected host organism.

Further topographical studies of the native P1 protein may lead to more detailed knowledge of the functional attachment sites and of the corresponding antigenic epitopes. This information will be of great importance if synthetic peptides are used as antigens in an ELISA for $M$. pneumoniae serology.

\section{ACKNOWLEDGMENTS}

This work was supported by grant 01 ZR 171 from the Bundesministerium für Forschung and Technologie.

The secretarial help of Ruth Thomas is gratefully acknowledged.

\section{LITERATURE CITED}

1. Baseman, J. B., R. M. Cole, D. C. Krause, and D. K. Leith. 1981. Molecular basis for cytadsorption of Mycoplasma pneumoniae. J. Bacteriol. 151:1514-1522.

2. Dallo, S. F., C. J. Su, J. R. Horton, and J. B. Baseman. 1988. Identification of $\mathrm{P} 1$ gene domain containing epitope(s) mediating Mycoplasma pneumoniae cytadherence. J. Exp. Med. 167: 718-723.

3. Eisenberg, D., E. Schwarz, M. Komaromy, and R. Wall. 1984. Analysis of membrane and surface protein sequences with the hydrophobic moment plot. J. Mol. Biol. 179:125-142.

4. Feldner, J., U. Göbel, and W. Bredt. 1982. Mycoplasma pneumoniae adhesin localized to tip structure by monoclonal antibody. Nature (London) 298:765-767.

5. Hopp, T. P., and K. R. Woods. 1981. Prediction of protein antigenic determinants from amino acid sequences. Proc. Natl. Acad. Sci. USA 78:3824-3828.

6. Hu, P. C., R. M. Cole, Y. S. Huang, J. A. Graham, D. E. Gardner, A. M. Collier, and W. A. Clyde, Jr. 1982. Mycoplasma pneumoniae infection: role of a surface protein in the attachment organelle. Science 216:313-315.

7. Hu, P. C., Y. S. Huang, J. A. Graham, and D. E. Gardner. 1981. Identification of immunogens of Mycoplasma pneumoniae by protein blotting. Biochem. Biophys. Res. Commun. 102:13631370. 
8. Inamine, M. J., T. P. Denny, S. Loechel, M. Schaper, C. H. Huang, K. F. Bott, and P. C. Hu. 1988. Nucleotide sequence of the P1-attachment protein gene of Mycoplasma pneumoniae. Gene 64:217-229.

9. Jacobs, E., A. Bennewitz, and W. Bredt. 1986. Reaction pattern of human anti-Mycoplasma pneumoniae antibodies in enzymelinked immunosorbent assays and immunoblotting. J. Clin. Microbiol. 23:517-522.

10. Jacobs, E., and A. Clad. 1986. Electroelution of fixed and stained membrane proteins from preparative sodium dodecyl sulfate polyacrylamide gels into a membrane trap. Anal. Biochem. 154:583-589.

11. Jacobs, E., K. Fuchte, and W. Bredt. 1986. A $168 \mathrm{kDa}$ protein of Mycoplasma pneumoniae used as antigen in a dot enzymelinked immunosorbent assay. Eur. J. Clin. Microbiol. 5:435440.

12. Jacobs, E., K. Schöpperle, and W. Bredt. 1985. Adherence inhibition assay: a specific serological test for detection of antibodies to Mycoplasma pneumoniae. Eur. J. Clin. Microbiol. 4:113-118.

13. Kamp, R. M. 1986. Separation of peptides, p. 8-20. In B. Wittmann-Liebold, J. Salnikow, and V. A. Erdmann (ed.), Advanced methods in protein microsequence analysis. Springer-Verlag, Berlin.
14. Leith, D. K., L. B. Trevino, J. G. Tully, L. B. Senterfit, and J. B. Baseman. 1983. Host discrimination of Mycoplasma pneumoniae proteinaceous immunogens. J. Exp. Med. 157:502-514.

15. Lottspeich, F. 1980. Identification of the phenyl-thiohydantoin derivates of amino acids by high pressure liquid chromatography, using a ternary, isocratic solvent system. Hoppe-Seyler's Z. Physiol. Chem. 361:1829-1834.

16. Matsudaira, P. 1987. Sequence from picomole quantities of proteins electroblotted onto polyvinylidene difluoride membranes. J. Biol. Chem. 262:10035-10038.

17. O'Farrell, P. 1975. High resolution two dimensional electrophoresis of proteins. J. Biol. Chem. 250:4007-4021.

18. Schapper, U., J. S. Chapman, and P. C. Hu. 1987. Preliminary indication of unusual codon usuage in the DNA coding sequence of the attachment protein of Mycoplasma pneumoniae. Isr. J. Med. Sci. 23:361-367.

19. Su, C. J., V. V. Tryon, and J. B. Baseman. 1987. Cloning and sequence analysis of cytadhesin P1 gene from Mycoplasma pneumoniae. Infect. Immun. 55:3023-3029.

20. Towbin, H., T. Staehlin, and J. Gordon. 1979. Electrophoretic transfer of proteins from polyacrylamide gels to nitrocellulose sheets. Procedure and some applications. Proc. Natl. Acad. Sci. USA 76:4350-4354. 